This work is licensed under a Creative Commons Attribution License (CC BY 4.0).

\title{
Gibbosaverruca weijiai, a new verrucid (Crustacea, Thoracica) species from the Weijia Guyot deep-sea seamount in the West Pacific
}

\author{
Zhibin GAN ${ }^{1, *}$, Dongsheng $Z \mathrm{ZHANG}^{2}$, Xinzheng $\mathrm{LI}^{3}$ \& Chunsheng WANG ${ }^{4,{ }^{*}}$ \\ ${ }^{1,3}$ Department of Marine Organism Taxonomy and Phylogeny, Institute of Oceanology, \\ Chinese Academy of Sciences, Qingdao, China. \\ ${ }^{2,4}$ Key Laboratory of Marine Ecosystem Dynamics, Second Institute of Oceanography, \\ Ministry of Natural Resources, Hangzhou, China. \\ ${ }^{1,3}$ Center for Ocean Mega-Science, Chinese Academy of Sciences, Qingdao, China. \\ ${ }^{3}$ Laboratory for Marine Biology and Biotechnology, Pilot National Laboratory for Marine Science and \\ Technology (Qingdao), Qingdao, China. \\ ${ }^{4}$ School of Oceanography, Shanghai Jiao Tong University, Shanghai, China. \\ *Corresponding authors: ganzhibin@qdio.ac.cn; wangsio@sio.org.cn \\ ${ }^{2}$ Email: dszhang@sio.org.cn \\ ${ }^{3}$ Email: lixzh@qdio.ac.cn \\ ${ }^{1}$ urn:lsid:zoobank.org:author:E6F40C5F-C0B4-485B-8446-25BE06BE6A10 \\ ${ }^{2}$ urn:lsid:zoobank.org:author:43C40412-F966-4F97-860F-0D27D3AA214C \\ ${ }^{3}$ urn:1sid:zoobank.org:author:3572ECD3-0D50-4294-8BCD-37D40D0A03F0 \\ ${ }^{4}$ urn:1sid:zoobank.org:author:E4014342-77B0-44F8-A6C0-4486853D02C5
}

\begin{abstract}
A new species of verrucid barnacle, Gibbosaverruca weijiai sp. nov., is described and illustrated based on specimens collected from a deep-sea seamount, Weijia Guyot, in the West Pacific. This is the third barnacle species reported from Weijia Guyot. The new species is distinguished from its congeners by its extremely long caudal appendage. In terms of shell morphology, G. weijiai sp. nov. is most similar to G. gibbosa and G. sulcata but differs from them by the intermediate articular ridges of its movable tergum and scutum, which are distinctly wider than the axial ridges. The COI and 16S rRNA sequences of the holotype of $G$. weijiai sp. nov. are presented to support future research, and a key to extant species of the genus Gibbosaverruca Young, 2002 is provided.
\end{abstract}

Keywords. Taxonomy, morphology, barnacle, identification key.

Gan Z., Zhang D., Li X. \& Wang C. 2021. Gibbosaverruca weijiai, a new verrucid (Crustacea, Thoracica) species from the Weijia Guyot deep-sea seamount in the West Pacific. European Journal of Taxonomy 739: 158-167. https://doi.org/10.5852/ejt.2021.739.1273

\section{Introduction}

The family Verrucidae Darwin, 1854 is a species-rich group of asymmetrical sessile barnacles mainly inhabiting deep waters. Young $(1998,2002,2004)$ performed excellent taxonomic work on a generic revision of the Verrucidae and described new genera and species. Currently, there are 12 extant genera identified in the family. Gibbosaverruca Young, 2002 is one of the genera separated from the genus 
Altiverruca Pilsbry, 1916 by Young (2002) based on external features of the shells. He placed G. gibbosa (Hoek, 1883), G. nitida (Hoek,1883), G. sulcata (Hoek, 1883), G. costata (Aurivillius, 1898), G. mitra (Hoek, 1907), G. darwini (Pilsbry, 1907), G. navicula (Hoek, 1913), G. rathbuniana (Pilsbry, 1916), G. somaliensis (Nilsson-Cantell, 1929), G. laeviscuta Buckeridge, 1994, G. montereyi Young, 2002, G. robusta Young, 2002 and G. mateoi Young, 2002 in this genus because they are all relatively large and possess opercular plates, a rostrum and a carina with pronounced growth lines and well-developed articular ridges on the surface. Recently, Gale (2020) reported three fossil species of Gibbosaverruca from the bathyal Upper Pliocene-Lower Pleistocene strata in the Rodrigues Ridge, Indian Ocean, including one new species, G. youngi Gale, 2020. However, many of the verrucid species are poorly described and lack any description of the soft body appendages, especially for the species described in the $19^{\text {th }}$ century. This condition causes some difficulties in the revision of verrucid taxa and results in some species with uncertain statuses.

Weijia Guyot (also known as Ita Mai Tai Guyot) is a Cretaceous-Early Cenozoic seamount located in the northwest Pacific $\left(12^{\circ} 50^{\prime} 0^{\prime \prime} \mathrm{N}, 156^{\circ} 50^{\prime} 0^{\prime \prime} \mathrm{E}\right)$, with a minimum depth of approximately $1400 \mathrm{~m}$ and a maximum depth of over $6000 \mathrm{~m}$ (Wedgeworth \& Kellogg 1987; Lee et al. 2003, 2005). Although several scientific expeditions have been executed in Weijia Guyot, only two barnacle species have been reported from the seamount: Scillaelepas ushakovi Zevina, 1988 and Arcoscalpellum angularum Gan, Xu, Li \& Wang, 2020 (Gan et al. 2020). In 2017, an investigation cruise (Voyage Dayang 41B) was carried out at Weijia Guyot and nearby seamounts by the Guangzhou Marine Geological Survey using the research vessel Haiyangliuhao. Several verrucid specimens were collected during this cruise. Detailed morphological examination indicates that these specimens represent a new verrucid species.

\section{Material and methods}

Specimens were collected from the peak plain of Weijia Guyot by the remotely operated vehicle (ROV) Haima. All specimens were preserved in $75 \%$ ethanol when taken on board. Morphological examination and molecular experiments were executed in the Department of Marine Organism Taxonomy and Phylogeny, Institute of Oceanology, Chinese Academy of Sciences. The specimens were deposited in the Sample Repository of the Second Institute of Oceanography (SRSIO), Ministry of Natural Resources of the People's Republic of China, Hangzhou.

Specimens were dissected using a stereo microscope (SMZ1500, Nikon, Japan) and photographed using a microscope integrated with an electronic imaging system (AZ100, Nikon, Japan). The measurement of each specimen is given as the basal rostro-carinal diameter (BD).

Total genomic DNA was extracted from the muscle of the thorax with the QIAamp DNA Mini Kit (QIAGEN, Hilden, Germany) following the manufacturer's instructions. Primers L1490 / H2 198 (Folmer et al. 1994) were used to amplify mitochondrial cytochrome oxidase subunit I (COI) gene fragment from the extracted genomic DNA, and primers16S-AR/16S-1472 (Crandall \& Fitzpatrick 1996) were used to amplify mitochondrial $16 \mathrm{~S}$ rRNA gene fragment via polymerase chain reaction (PCR). The PCR was carried out in a 50- $\mu$ l volume containing $25 \mu 1$ Premix Taq (TransGen, Beijing, China), $1 \mu 1$ each of the forward and reverse primers $(10 \mu \mathrm{M}), 3 \mu \mathrm{l}$ DNA template, and $20 \mu \mathrm{l}$ ultrapure water. The PCR procedure was performed by initial denaturation at $94^{\circ} \mathrm{C}$ for $5 \mathrm{~min}, 35$ cycles of denaturation at $94^{\circ} \mathrm{C}$ for $30 \mathrm{~s}$, annealing at $50-52^{\circ} \mathrm{C}$ for $40 \mathrm{~s}$, elongation at $72^{\circ} \mathrm{C}$ for $50 \mathrm{~s}$, and a final extension at $72^{\circ} \mathrm{C}$ for $10 \mathrm{~min}$. The PCR products were purified using the QIAquick Gel Extraction Kit (Qiagen, Hilden, Germany) and bidirectionally sequenced with the same primers by an ABI 3730xl Analyzer (Applied Biosystems, Foster City, USA). Chromatograms and sequences were checked and proofread by ContigExpess 6.0 (LifeTechnologies, Carlsbad, United States). Final sequences were submitted to GenBank (https://www.ncbi.nlm.nih.gov/). 


\section{Results}

Subphylum Crustacea Brünnich, 1772

Superorder Thoracica Darwin, 1854

Order Sessilia Lamarck, 1818

Family Verrucidae Darwin, 1854

Genus Gibbosaverruca Young, 2002

Gibbosaverruca weijiai sp. nov.

urn:lsid:zoobank.org:act:C0F9728C-1D03-4E52-BBE4-053C9586095D

Figs 1-4; Table 1

\section{Diagnosis}

All plates with prominent growth lines. External surface of rostrum with four ridges, uppermost largest, upper margin of rostrum sloping down to base of movable scutum, faint ridge between them. Movable

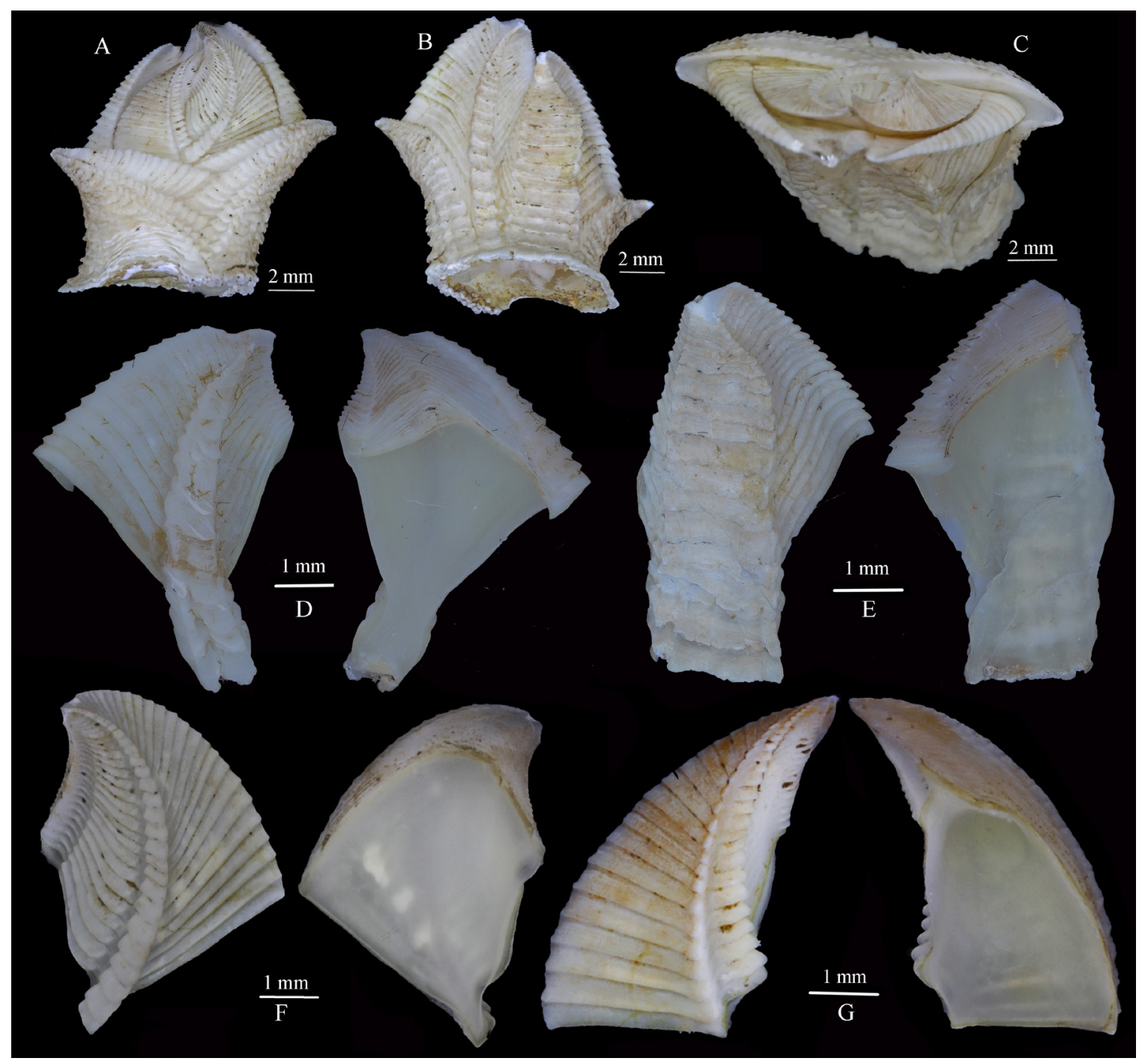

Fig. 1. Gibbosaverruca weijiai sp. nov., holotype, SRSIO17090313. A. Opercular plates. B. Fixed tergum and scutum. C. From above. D. Fixed tergum. E. Fixed scutum. F. Movable tergum. G. Movable scutum. 
tergum with three articular ridges, axial ridge strongly prominent, intermediate ridge widest. Movable scutum with three articular ridges, axial ridge thin, second ridge prominent, wider than axial ridge. Cirrus I and cirrus II with anterior rami no more than half length of posterior rami. Intermediate segments of cirrus VI with three pairs of setae on anterior margin. Caudal appendage very long, more than five times as long as protopodite.

\section{Etymology}

The new species is named after its type locality, Weijia Guyot, the West Pacific.

\section{Material examined}

\section{Holotype}

WEST PACIFIC • measurements BD $=10.29 \mathrm{~mm}$; roof deck of Weijia Guyot; 156 41'15.72" E, $12^{\circ} 47^{\prime} 22.20^{\prime \prime} \mathrm{N}$; depth 1935 m; 21 Sep. 2017; crews of ROV Haima leg.; Stn MCROV06; Dayang 41B cruise; attached to sponge remains; GenBank: MW033972 (COI), MW033931 (16S rRNA); SRSIO17090313.

\section{Paratype}

WEST PACIFIC $\bullet 6$ specimens, measurements $\mathrm{BD}=7.82-10.36 \mathrm{~mm}$; same collection data as for holotype; attached to sponge remains; SRSIO17090314 3 specimens, measurements BD $=8.05$ $9.12 \mathrm{~mm}$; roof deck of Weijia Guyot; 156 $17^{\prime} 13.56^{\prime \prime}$ E, 12²2'37.92" N; depth $1995 \mathrm{~m}$; 22 Sep. 2017; crews of ROV Haima leg.; Stn MCROV02; Dayang 41B cruise; attached to sponge remains; SRSIO17090314.

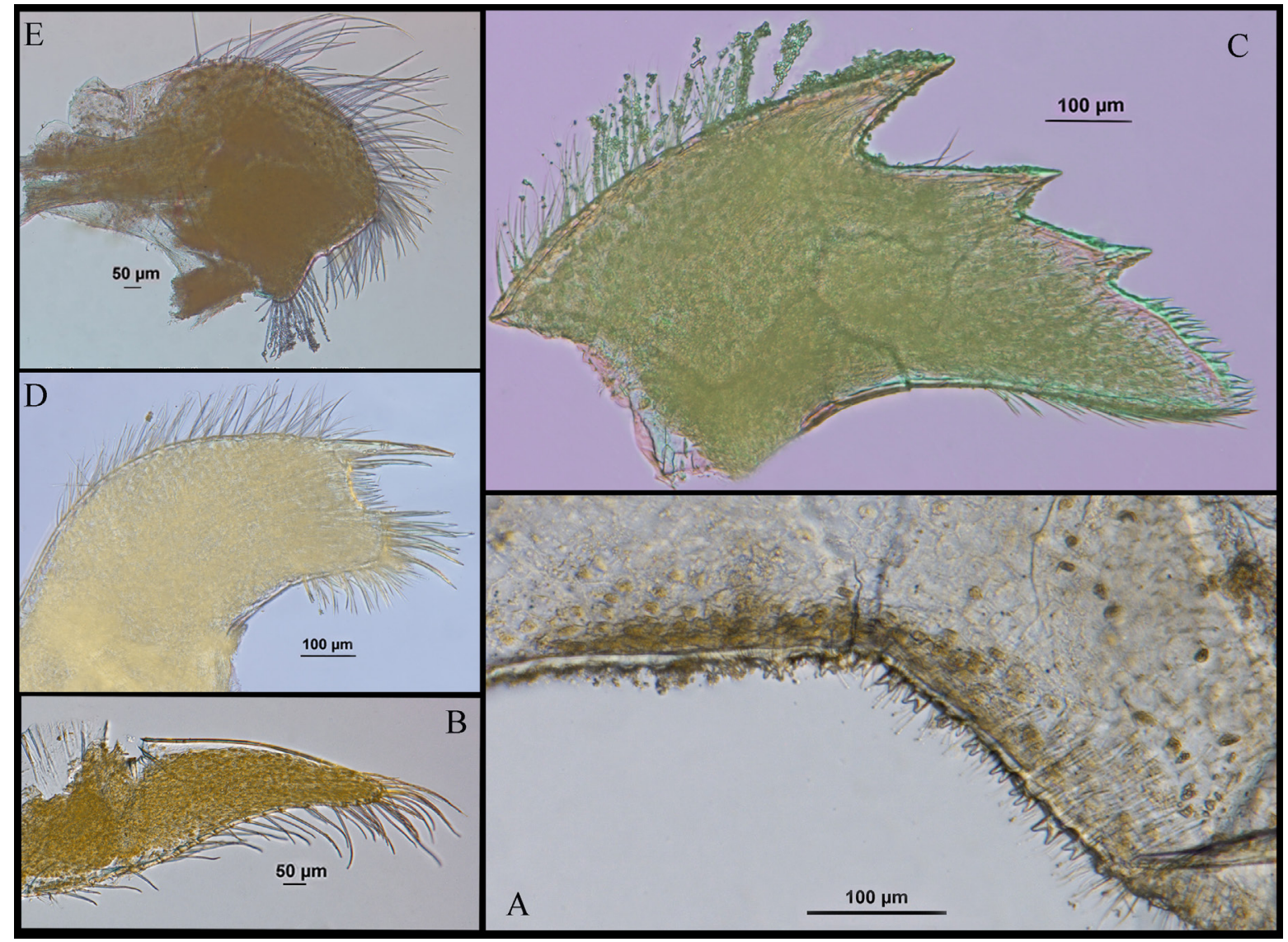

Fig. 2. Gibbosaverruca weijiai sp. nov., holotype, SRSIO17090313. A. Inner edge of labrum. B. Palp. C. Mandible. D. Maxillule. E. Maxilla. 


\section{Description}

Large-sized verrucid species. Shell white, growth lines prominent on all plates. Apices of rostrum and carina projecting well beyond margins of fixed tergum and fixed scutum (Fig. 1A-C). Rostrum and carina interlocking by four articular ridges (Fig. 1A), with narrow grooves between them on rostrocarinal articulation. Rostrum lower but longer than carina; anterior surface with four ridges, uppermost largest, as wide as following three ridges combined, lowest ridge faint; upper margin of rostrum sloping down to base of movable scutum, faint ridge between them terminating at end of axial ridge of carina. Carina with four articular ridges, first two similar in width, larger than following two; lowest ridge feebly developed.

Fixed tergum (Fig. 1B, D) higher than fixed scutum, axial ridge prominent, narrow, both sides with welldeveloped alar-like projections; apex flexed towards fixed scutum. Axial ridge of fixed scutum (Fig. 1B, E) wide, about three times width of fixed tergum; alar-like process directed toward rostrum, wide, about two times width of radius-like process, directed toward fixed tergum; apex straight.

Movable tergum (Fig. 1A, F) quadrangular, with three articular ridges; axial ridge prominent, narrow groove between it and intermediate ridge; intermediate ridge very wide, triangular, about three times width of axial ridge; broad groove between intermediate ridge and upper ridge; upper ridge thin, submarginal; internal surface smooth. Movable scutum (Fig. 1A, G) triangular, smaller than movable tergum; three articular ridges, axial ridge narrow, low, intermediate ridge largest, prominent, upper ridge short, sub-marginal; area between intermediate ridge and upper ridge smooth, without growth line; internal surface smooth.

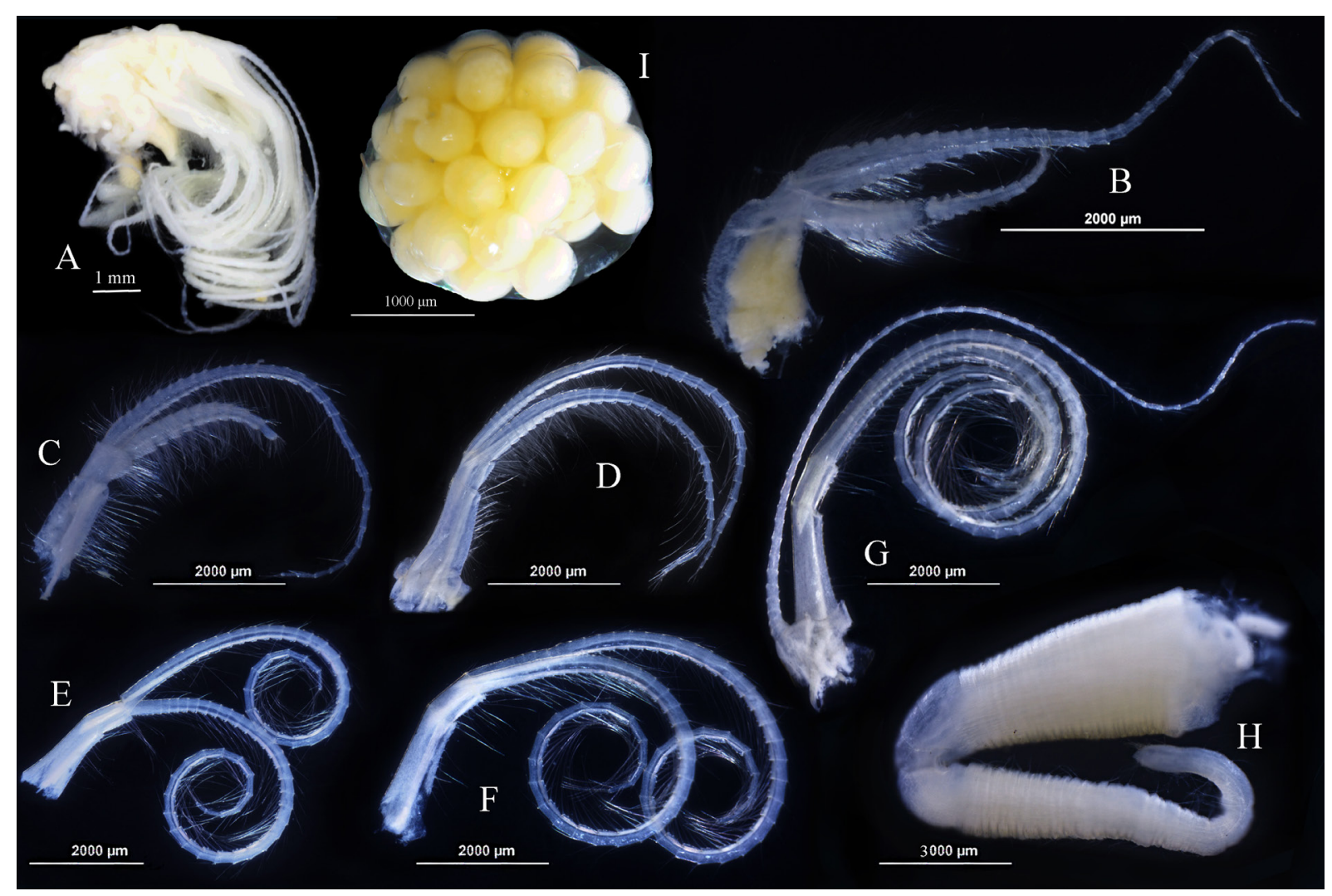

Fig. 3. Gibbosaverruca weijiai sp. nov., holotype, SRSIO17090313. A. Soft body. B. Cirrus I. C. Cirrus II. D. Cirrus III. E. Cirrus IV. F. Cirrus V. G. Cirrus VI. H. Penis. I. Eggs. 
Labrum (Fig. 2A) with line of bifid or trifid teeth. Palp (Fig. 2B) narrow, with simple setae on terminal and inner margin. Mandible (Fig. 2C) with three teeth, first larger than following two; inferior angle acute, superior border armed with series of spinules. Cutting edge of maxillule (Fig. 2D) inflected; upper angle with large spine and some cuspidate setae; lower region projecting, furnished with cuspidate setae. Anterior margin of maxilla (Fig. 2E) with small notch, upper and anterior margins covered by long setae.

Soft body (Fig. 3) without filamentary appendage. Cirrus I separated from, and shorter, sturdier than cirri II-VI (Fig. 3B), coxopodite inflated; anterior ramus slightly shorter than half length of posterior ramus; both rami with wide basal segments tapering distally. Cirrus II (Fig. 3C) with anterior ramus slightly shorter than half length of posterior ramus. Cirri III-VI (Fig. 3D-G) with rami subequal; intermediate segments of cirrus VI with two pairs of long setae and one pair of short setae on anterior margin. Caudal appendage (Fig. G) very long, more than five times length of protopodite, with more than 50 segments.

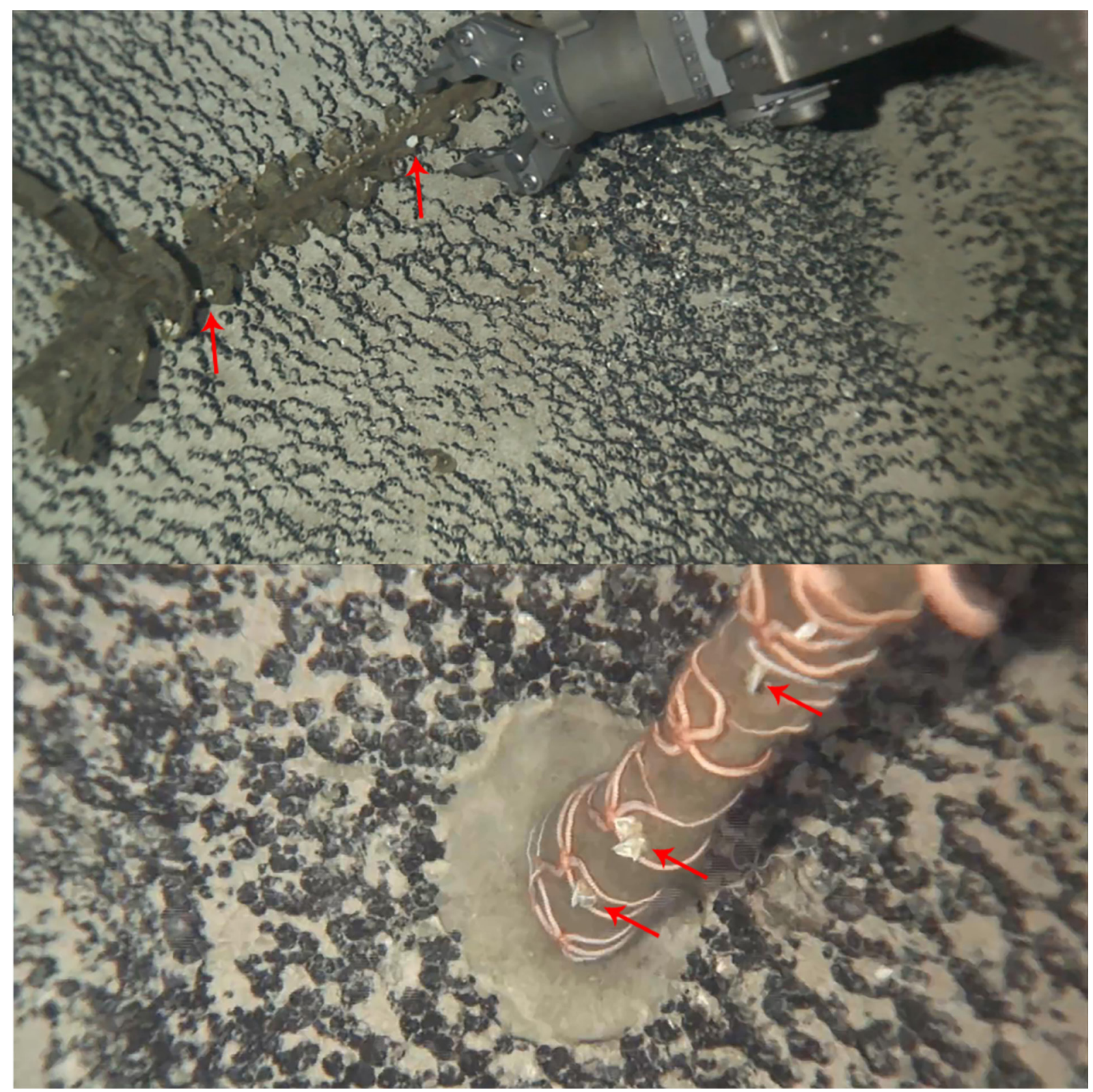

Fig. 4. In situ figures of Gibbosaverruca weijiai sp. nov. (red arrows). 
Table 1. Number of segments on cirri I-VI and caudal appendage of the holotype of Gibbosaverruca weijiai sp. nov.

\begin{tabular}{lccccccc}
\hline & \multicolumn{9}{c}{ Cirri } & \multirow{2}{*}{ Caudal appendage } \\
& I & II & III & IV & V & VI & \\
\hline left & $18 / 29$ & $12 / 32$ & $27 / 31$ & $36 / 40$ & $41 / 45$ & $48 / 49$ & 51 \\
right & $18 / 30$ & $13 / 31$ & $29 / 32$ & $35 / 38$ & $43 / 45$ & $47 / 50$ & 50 \\
\hline
\end{tabular}

Number of segments of cirri I-VI and caudal appendage are presented in Table 1. Penis (Fig. $3 \mathrm{H}$ ) robust, tapering, surface with annular wrinkles. Eggs (Fig. 3I) globular, encompassed by transparent film capsule.

\section{Habitat and distribution}

Roof deck of Weijia Guyot, depth 1935-1995 m, attached to sponge remains (Fig. 4). Currently only known from the type locality, Weijia Guyot.

\section{Key to the extant species of the genus Gibbosaverruca Young, 2002.}

1. Movable scutum not flat, with distinct articular ridges

- Movable scutum flat, apico-basal line defined by growth-line deflection

G. laeviscuta Buckeridge, 1994

2. Movable scutum with three or more articular ridges ................................................................... 3

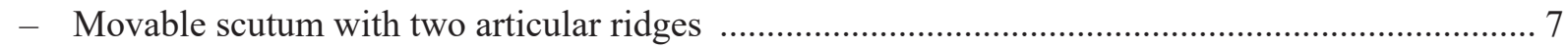

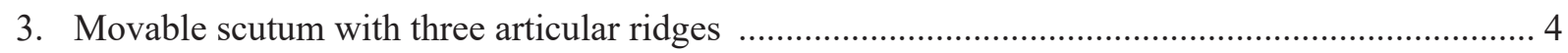

- Movable scutum with four articular ridges ...................................................navicula (Hoek, 1913)



- Movable tergum with four articular ridges ................................................... robusta Young, 2002

5. Intermediate ridge of movable tergum about three times width of axial ridge, caudal appendage extremely long, more than five times length of protopodite

G. weijiai sp. nov.

- Intermediate ridge of movable tergum about same width of axial ridge, caudal appendage short .. 6

6. Radius-like process of fixed scutum well-developed, apices of rostrum and carina strongly projecting

G. sulcata (Hoek, 1883)

- Radius-like process of fixed scutum small, apices of rostrum and carina slightly or not projecting .

G. gibbosa (Hoek, 1883)

7. Movable tergum with three articular ridges, caudal appendage short, no more than two times as long as protopodite

- Movable tergum with two articular ridges, caudal appendage long, more than two times as long as protopodite

G. nitida (Hoek, 1883)

8. Rostrum with flat surface from upper margin to basal margin of scutum ..................................... 9

- Rostrum without flat surface from upper margin to basal margin of scutum ................................... 10

9. Rostrum upper surface with one small ridge turned toward scutum ............ G. mateoi Young, 2002

- Rostrum upper surface without ridge ........................................................ G. darwini (Pilsbry, 1907) 
10. Rostrum and carina each with no more than four articular ridges

- Rostrum and carina each with five articular ridges G. montereyi Young, 2002

11. Uppermost ridge of carina terminating at end of axial ridge of movable tergum 12

- Uppermost ridge of carina exceeding end of axial ridge of movable tergum

G. costata (Aurivillius, 1898)

12. Intermediate ridge of movable scutum about same width as axial ridge

- Intermediate ridge of movable scutum about two times wider than axial ridge

G. somaliensis (Nilsson-Cantell, 1929)

13. Rostrum with two articular ridges of same width

G. mitra (Hoek, 1907)

- Rostrum with three articular ridges, second largest

G. rathbuniana (Pilsbry, 1916)

\section{Discussion}

Based on its robust appearance and the multiple strong ridges articulating the rostrum and the carina, the new species is easily placed in the genus Gibbosaverruca, despite the overlapping diagnostic characters of the genera Altiverruca and Gibbosaverruca (the suture of the rostrum and carina) (Pilsbry 1916; Gruvel 1920; Young 2002). Gibbosaverruca weijiai sp. nov. is distinguishable from all extant species of Gibbosaverruca by having relatively long caudal appendage (more than 50 segments), which are unique in the genus. Gibbosaverruca navicula and G. nitida also have a relatively long caudal appendage compared with those of other species of Gibbosaverruca, but both have caudal appendages with no more than 35 segments. The numbers and profiles of the articular ridges of the movable tergum and movable scutum are also very different from those of G. weijiai sp. nov. (Buckeridge 1994).

In terms of external shell morphology, Gibbosaverruca weijiai sp. nov. is most similar to G. gibbosa and G. sulcata. All three species have three articular ridges on the movable tergum and movable scutum, and their rostrum and carina united by two or more strong ridges. However, G. weijiai sp. nov. differs from G. gibbosa by the strongly projecting apices of the rostrum and carina (not or only slightly projecting in G. gibbosa) and the relatively wide intermediate ridge of the movable tergum (three times as wide as the axial ridge vs the same width as the axial ridge) (Hoek 1883; Young 1998, 2002). Gibbosaverruca weijiai sp. nov. is distinguished from G. sulcata by the intermediate ridges of the movable tergum and movable scutum (distinctly wider than the axial ridge vs the same width as the axial ridge) and by the radius-like process of the fixed scutum (vestigial and small vs well-developed and large) (Hoek 1883; Young 2002). Based on fossils of the fixed scutum and fixed tergum, Gale described one new species (G. youngi) and two unnamed species (Gibbosaverruca sp. 1 and Gibbosaverruca sp. 2) from the Indian Ocean (Gale 2020), and these three species are also different from G. weijiai sp. nov. First of all, G. youngi and Gibbosaverruca sp. 2 have a fixed scutum bearing a well-developed radius-like process and a narrower occludent wing compared with $G$. weijiai sp. nov. Secondly, the imbricate flanges on the exterior surface of the fixed scutum of G. youngi are furnished with short pustules (see Gale 2020). Furthermore, Gibbosaverruca sp. 1 has a fixed tergum presenting strongly convex occludent and carinal margins, which is very unusual in the verrucid species (Gale 2020). In terms of internal soft body morphology, G. weijiai sp. nov. differs from G. gibbosa and G. sulcata by the very unequal lengths of the anterior and posterior rami of cirrus I and the extremely long caudal appendages (Young 2002). 


\section{Acknowledgements}

Great appreciations are expressed to the crews of vessel Haiyangliuhao and ROV Haima for their help in collecting the specimens. The present work was supported financially by the China Ocean Mineral Resources R\&D Association Special Foundation (Nos DY135-E2-2-03, DY135-E2-2-06, and DY135-E2-3-04).

\section{References}

Buckeridge J.S. 1994. Cirripedia Thoracica: Verrucomorpha of New Caledonia, Indonesia, Wallis and Futuna Islands. In: Crosnier A. (ed.) Résultats des Campagnes MUSORSTOM 12. Mémoires du Muséum national d'histoire naturelle. Série A, Zoologie 161: 87-125.

Crandall K.A. \& Fitzpatrick J.F. Jr 1996. Crayfish molecular systematics: using a combination of procedures to estimate phylogeny. Systematic Biology 45 (1): 1-26. https://doi.org/10.1093/sysbio/45.1.1

Folmer O., Black M., Hoeh W., Lutz R. \& Vrijenhoek R. 1994. DNA primers for amplification of mitochondrial cytochrome c oxidase subunit I from diverse metazoan invertebrates. Molecular Marine Biology and Biotechnology 3 (5): 294-299.

GaleA.S. 2020. Bathyal Pliocene-Early Pleistocene cirripedes (Crustacea, Thoracica) from the Rodrigues Ridge, Mascarene Plateau, Indian Ocean. Part 1. Cainozoic Research 20 (2): 151-188.

Gan Z., Xu P., Li X. \& Wang C. 2020. Integrative taxonomy reveals two new species of stalked barnacle (Cirripedia, Thoracica) from seamounts of the western Pacific with a revie arnacles distributed in seamounts worldwide. Frontiers in Marine Science 7: 582225.

https://doi.org/10.3389/fmars.2020.582225

Gruvel J.A. 1920. Cirrhipèdes provenant des Campagnes scientifiques de SAS le Prince de Monaco (1885-1913). Imprimerie de Monaco, Monaco.

Hoek P.P.C. 1883. Report on the Cirripedia collected by H.M.S. Challenger during the years 1873-76. Reports of Science Research Voyage of H.M.S. Challenger, Zoology 8 (25): 1-169.

Lee T.G., Lee S.M., Moon J.W. \& Lee K. 2003. Paleomagnetic investigation of seamounts in the vicinity of Ogasawara Fracture Zone northwest of the Marshall Islands, western Pacific. Earth, Planets and Space 55 (6): 355-360. https://doi.org/10.1186/BF03351769

Lee T.G., Hei J.R., Lee K., Moon J.W. \& Ko Y.T. 2005. Sub-seafloor acoustic characterization of seamounts near the Ogasawara Fracture Zone in the western Pacific using chirp $(3-7 \mathrm{kHz})$ subbottom profiles. Deep Sea Research Part I: Oceanographic Research Papers 52 (10): 1932-1956. https://doi.org/10.1016/j.dsr.2005.04.009

Pilsbry H.A. 1916. The sessile barnacles (Cirripedia) contained in the collections of the U.S. National Museum, including a monograph of the American species. Bulletin of the United States National Museum 93: 1-366. https://doi.org/10.5479/si.03629236.93.1

Wedgeworth B.S. \& Kellogg J.N. 1987. A 3-D gravity tectonic study of Ita Mai Tai Guyot: an uncompensated seamount in the East Mariana Basin. Geophysical Monograph Series 43: 73-84. https://doi.org/10.1029/GM043p0073

Young P.S. 1998. Cirripedia (Crustacea) from the "Campagne Biaçores" in the Azores region, including a generic revision of the Verrucidae. Zoosystema 20 (1): 31-92.

Young P.S. 2002. The Verrucidae (Crustacea, Cirripedia) from the western coast of North America, with a revision on the genus Altiverruca. Arquivos do Museu Nacional 60 (1): 5-40. 
Young P.S. 2004. Globuloverruca spongophila gen. nov., sp. nov., a sponge-associated verrucid (Crustacea: Cirripedia: Thoracica) from Easter Island, with discussion on the morphology of the plate tubules. Zootaxa 420: 1-10. https://doi.org/10.11646/zootaxa.420.1.1

Manuscript received: 27 September 2020

Manuscript accepted: 12 January 2021

Published on: 18 March 2021

Topic editor: Rudy C.A.M. Jocqué

Desk editor: Radka Rosenbaumová

Printed versions of all papers are also deposited in the libraries of the institutes that are members of the EJT consortium: Muséum national d'histoire naturelle, Paris, France; Meise Botanic Garden, Belgium; Royal Museum for Central Africa, Tervuren, Belgium; Royal Belgian Institute of Natural Sciences, Brussels, Belgium; Natural History Museum of Denmark, Copenhagen, Denmark; Naturalis Biodiversity Center, Leiden, the Netherlands; Museo Nacional de Ciencias Naturales-CSIC, Madrid, Spain; Real Jardín Botánico de Madrid CSIC, Spain; Zoological Research Museum Alexander Koenig, Bonn, Germany; National Museum, Prague, Czech Republic. 